\title{
Preparation of a Novel Block Copolymer by the Anionic Polymerization of a Bicyclic Oxalactam Activated with Isocyanate-Terminated Polyoxyethylene and Characterization of Its Hydrophilic Membrane
}

\author{
Kazuhiko Hashimoto, Hiroshi Sumitomo, and Hiroo YAMAMORI \\ Faculty of Agriculture, Nagoya University, Chikusa-ku, Nagoya 464, Japan
}

(Received August 3, 1984)

\begin{abstract}
A new block copolymer composed of polyamide as outer segments and polyoxyethylene as an inner segment was prepared by the anionic polymerization of a bicyclic oxalactam, 8-oxa-6-azabicyclo[3.2.1]octan-7-one. A polyoxyethylene having terminal isocyanate groups was used as an activator obtained from polyoxyethylene glycol and an excess of tolylene2,4-diisocyanate. A hydrophilic membrane was easily obtained by casting from a chloroformmethanol $(10: 1)$ solution of the resulting block copolymer. The interaction of the copolymer membrane with water molecules was discussed in relation to the adsorption and permeation of water.
\end{abstract}

KEY WORDS Bicyclic Oxalactam / 8-Oxa-6-azabicyclo[3.2.1]octan-7-one /

Block Copolymer / Polyoxyethylene / Polyamide / Hydrophilic

Membrane / Permeability /

Bicyclic oxalactam, 8-oxa-6-azabicyclo[3.2.1] octan-7-one (abbreviated as BOL, 1) has so high a polymerizability that the anionic polymerization proceeds under mild conditions such as room temperature in solution..$^{1-3}$ The resulting high molecular weight polyamide 2 can be cast as the hygroscopic membrane with a high permeability of water and permselectivity for solutes of various size in solution. ${ }^{2,4-6}$ Such a novel polyamide is ex-
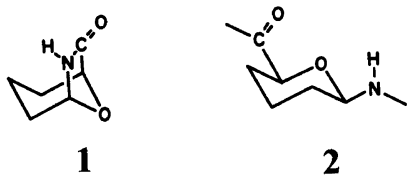

pected to become available for block- and graft copolymers.

Recently, we reported syntheses of polyamide macromers having telechelic amino groups and a vinylbenzyl group, respectively, from BOL (1). ${ }^{7,8}$ The radical copolymerization of the latter with styrene yielded a well-defined graft copolymer consisting of a nonpolar polystyrene stock and polar hydrophilic polyamide branches. ${ }^{8}$ The present article describes the preparation of a block copolymer having hydrophilic polyamide and polyoxyethylene segments (3) and characterization of its hydrophilic membrane.

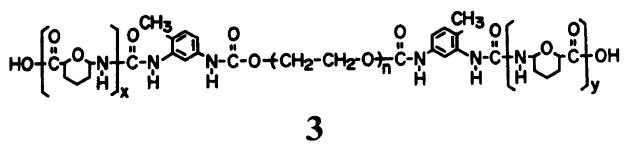

\section{EXPERIMENTAL}

\section{Reagents}

BOL was prepared by the same procedure as reported previously, ${ }^{1,2}$ and stored over phosphorus pentoxide in vacuo unitl use. Potassium pyrrolidonate (K-Pyrdn) was prepared as described in the literature. ${ }^{9}$ Polyoxyethylene glycols (POE-OH) with molecular weights of 1030,2850 , and 8900 were purified by reprecipitation with diethyl ether 
from their benzene solutions, and lyophilized. Tolylene-2,4-diisocyanate (TDI) was distilled after being kept in a vacuum line for more than a week. Dimethyl sulfoxide $\left(\mathrm{Me}_{2} \mathrm{SO}\right)$ was first distilled under reduced pressure after drying over calcium hydride, and the main fraction was dried over molecular sieves in a high vacuum line for several days, followed by redistillation in vacuo. Dichloromethane, carbon tetrachloride, and diethyl ether were also distilled after drying over molecular sieves, molecular sieves, and sodium metal, respectively, in a high vacuum line.

\section{Preparation of Polyoxyethylene Telechelated with Isocyanate Groups}

All the procedures were carried out in a high vacuum system. To a solution of $3.73 \mathrm{~g}$ of POE-OH $\left(M_{n}, 2850\right)$ in $50 \mathrm{ml}$ of dichloromethane in a flask $8.7 \mathrm{~g}$ of TDI were added with stirring, and the resulting solution stood at $38^{\circ} \mathrm{C}$ for 4 days. After the solvent was distilled out, $250 \mathrm{ml}$ of diethyl ether were poured into the residue to precipitate the modified polyoxyethylene. The resulting white polymer was collected and washed with diethyl ether more than 8 times in a vacuum line to prevent contamination with unreacted TDI. The isolated polyoxyethylene was then dried and stored in a closed ampoule until use; yield, $3.06 \mathrm{~g}$. To estimate the isocyanate group content in the modified polyoxyethylene, a small portion was taken out and treated with ethanol in the atmosphere. The terminal (4-methyl-1,3-phenylene)biscarbamic acid ester group formed was determined by UV spectroscopy.

\section{Anionic Polymerization of BOL Activated by}

Telechelic Polyoxyethylene with Isocyanate Groups

In a high vacuum line, $4.5 \mathrm{~g}$ of $\mathrm{BOL}$ and $45 \mathrm{mg}$ of K-Pyrdn were dissolved in $8 \mathrm{~g}$ of $\mathrm{Me}_{2} \mathrm{SO}$ in a flask. To this solution was immediately added a solution of the isocyanateterminated polyoxyethylene $\left(M_{n}, 3250 ; 0.98 \mathrm{~g}\right)$ in $8 \mathrm{~g}$ of $\mathrm{Me}_{2} \mathrm{SO}$ with vigorous stirring. The reaction mixture was kept at $25^{\circ} \mathrm{C}$ for $1 \mathrm{~h}$. After polymerization, the contents were placed in a large amount of acetone, and the product was minced and immersed repeatedly in fresh acetone to remove any residual monomer, catalyst, and solvent. The resulting white polymer was collected on a glass filter, washed again with acetone, and dried in vacuo at room temperature; yield, $3.88 \mathrm{~g}$. In some runs the same procedure was carried out under nitrogen atmosphere.

\section{Characterization}

The UV spectrum was measured with a JASCO UVIDEC-1 spectrophotometer. The gel permeation chromatogram was recorded on a Hitachi Model 634A high performance liquid chromatograph (column, Shodex GPCA $80 \mathrm{M}, 8 \phi \times 1000 \mathrm{~mm}$; solvent, chloroform). ${ }^{1} \mathrm{H}$ NMR and ${ }^{13} \mathrm{C}$ NMR spectra were taken with JEOL JNM-FX-100 and JNM-FX200 Fourier transform high resolution spectrometers. Moisture sorption was determined gravimetrically at $20^{\circ} \mathrm{C}$. The relative humidity was controlled by varying the ratio of concentrated sulfuric acid to water. The block copolymer membrane was obtained by casting from a $3 \%$ chloroform-methanol (10:1) solution of the copolymer and drying at room temperature. Water permeation and solute rejection through the copolymer membrane were measured with a commercial ultrafiltration cell. $^{2,4,10}$ The effective membrane area was $13.9 \mathrm{~cm}^{2}$. The DSC thermograms of the membrane containing various amounts of water were taken with a Perkin-Elmer Model 2 differential scanning calorimeter at temperatures from $-60^{\circ} \mathrm{C}$ to $25^{\circ} \mathrm{C} .^{6}$

\section{RESULTS AND DISCUSSION}

\section{Polyoxyethylene Telechelated with Isocyanate Groups}

To obtain a block copolymer consisting of polyamide as outer segments and poly- 
Block Copolymer from Bicyclic Oxalactam

Table I. Preparation of telechelic polyoxyethylene with isocyanate groups

\begin{tabular}{|c|c|c|c|c|c|c|c|c|c|c|}
\hline \multirow{2}{*}{$\begin{array}{l}\text { Run } \\
\text { No. }\end{array}$} & \multicolumn{2}{|c|}{$\mathrm{POE}-\mathrm{OH}$} & \multirow{2}{*}{$\frac{\mathrm{TDI}}{\mathrm{g}}$} & \multicolumn{2}{|c|}{ Solvent } & \multirow{2}{*}{$\frac{\text { Temp }}{{ }^{\circ} \mathrm{C}}$} & \multirow{2}{*}{$\begin{array}{c}\text { Time } \\
\text { day }\end{array}$} & \multirow{2}{*}{$\frac{\text { Yield }^{\mathrm{a}}}{\mathrm{g}}$} & \multirow{2}{*}{$N^{\mathrm{b}, \mathrm{c}}$} & \multirow{2}{*}{$M_{n}^{\mathrm{c}}$} \\
\hline & $M_{n}$ & $\mathrm{~g}$ & & & $\mathrm{ml}$ & & & & & \\
\hline 1 & 1030 & 2.03 & 4.2 & $\mathrm{CCl}_{4}$ & 50 & 60 & 0.2 & $1.73^{\mathrm{d}}$ & 1.72 & 1550 \\
\hline 2 & 1030 & 1.25 & 8.7 & $\mathrm{CH}_{2} \mathrm{Cl}_{2}$ & 60 & 39 & 4 & 0.96 & 1.99 & 1380 \\
\hline 3 & 2850 & 3.73 & 8.7 & $\mathrm{CH}_{2} \mathrm{Cl}_{2}$ & 50 & $\sim 20$ & 4 & $3.62^{\mathrm{d}}$ & - & - \\
\hline 4 & 2850 & 3.73 & 8.7 & $\mathrm{CH}_{2} \mathrm{Cl}_{2}$ & 50 & 38 & 4 & 3.06 & 2.01 & 3250 \\
\hline 5 & 8900 & 20.3 & 17.4 & $\mathrm{CH}_{2} \mathrm{Cl}_{2}$ & 120 & 38 & 1 & $-^{\mathrm{e}}$ & - & - \\
\hline 6 & 8900 & 10.2 & 8.7 & $\mathrm{CCl}_{4}$ & 110 & 55 & $0.2_{5}$ & $6.55^{\mathrm{d}}$ & - & - \\
\hline
\end{tabular}

a Diethyl ether insoluble polymer.

b Average number of introduced isocyanate groups per fed polyoxyethylene chain before reaction with ethanol.

c Estimated from terminal biscarbamic acid ester group content determined by UV spectroscopy following treatment with ethanol.

d Accompanied by polyaddition reaction of the hydroxyl group in the unreacted polyoxyethylene chain with the isocyanate group introduced in the other chain.

e Resinified.

oxyethylene as an inner segment (3), a polyoxyethylene having terminal isocyanate groups (POE-NCO, 4) was first prepared (see eq 1).

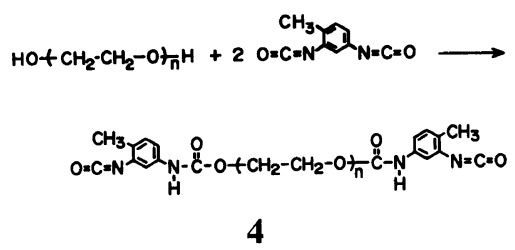

The polyaddition reaction between polyoxyethylene glycol (POE-OH) and tolylene2,4-diisocyanate (TDI) is known well as an important step for the preparation of "segmented" polyurethanes. ${ }^{11}$ Methods for the preparation and isolation of the polyoxyethylene, which was quantitatively terminated with isocyanate groups without contaminating with the unreacted TDI, were examined as a first step in the present work. The procedure described in the experimental section was used in a high vacuum line system. Commercially available $\mathrm{POE}-\mathrm{OH}$ of various molecular weights $(1030,2850$, and 8900$)$ were reacted with an excess of TDI under the conditions listed in Table I.

For estimation of the isocyanate group con- tent in the modified polyoxyethylene, a small portion of it was treated with an excess of ethanol, and the terminal (4-methyl-1,3phenylene)biscarbamic acid ester formed was determined by UV spectroscopy using diethyl (4-methyl-1,3-phenylene)biscarbamate as a model compound $\left(\varepsilon_{\max }, 1820\right.$ at $286 \mathrm{~nm}$ in chloroform). When about a 40 times excess of TDI was used in the reactions with $\mathrm{POE}-\mathrm{OH}$ $\left(M_{n}, 1030\right.$ and 2850$)$ at $38-39^{\circ} \mathrm{C}$ for 4 days, isocyanate groups were introduced almost quantitatively at both ends of the polyoxyethylene chain (run No. 2 and 4 in Table I). With a comparatively small excess of TDI (run No. 1 in Table I), the content of this group in the modified polyoxyethylene was found to be 1.72 per one polyoxyethylene chain fed. Some of polyoxyethylene chains may have been coupled with each other by the polyaddition reaction between the unreacted hydroxyl group in the polyoxyethylene chain and an isocyanate group introduced in the other polyoxyethylene chain. This is supported by the gel permeation chromatography. A similar run at room temperature (run No. 3) and other runs using high molecular weight $\mathrm{POE}-\mathrm{OH}$ (run No. 5 and 6) were not as satisfactory due to the above-mentioned 


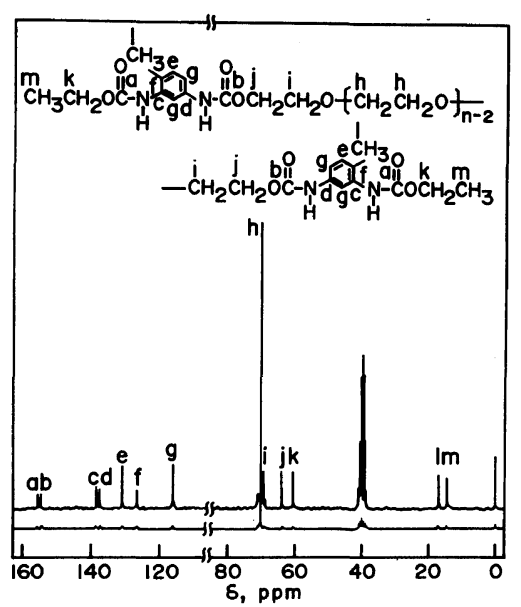

Figure 1. ${ }^{13} \mathrm{C}$ NMR spectrum of the reaction product of polyoxyethylene having terminal isocyanate groups with ethanol $\left(M_{n}, 3340\right)\left(10 \% \mathrm{Me}_{2} \mathrm{SO}-d_{6}\right.$ solution, TMS, $60^{\circ} \mathrm{C}, 50 \mathrm{MHz}$ ).

polyaddition reaction. Since the solubility of POE-OH in organic solvents depends on its molecular weight and decrease with temperature, the poor solubility of high molecular weight $\mathrm{POE}-\mathrm{OH}$ at lower temperature may cause an increase in the local concentration of the hydroxyl group. This should be favorable to the intermolecular polyaddition reaction.

Figure 1 is a typical ${ }^{13} \mathrm{C}$ NMR spectrum of the polyoxyethylene modified by a reaction with an excess of TDI followed by treatment with ethanol $\left(M_{n}, 3340\right)$. The figure also shows that the modified polyoxyethylene had terminated with isocyanate groups at both chain ends prior to treatment with ethanol.

\section{Block Copolymer Having Polyamide and} Polyoxyethylene Segments

The anionic polymerization of lactams is markedly accelerated by the addition of a small amount of isocyanates as well as acyllactams. Thus isocyanates can react rapidly with lactam anions to give corresponding acyllactam-type growing ends. In the anionic polymerization of $\mathrm{BOL}$, the initiation and propagation reactions activated with POENCO (4) $\left(M_{n}, 1550\right.$ and 3250) as activators are shown in eq 2 and 3, respectively. The polymer-
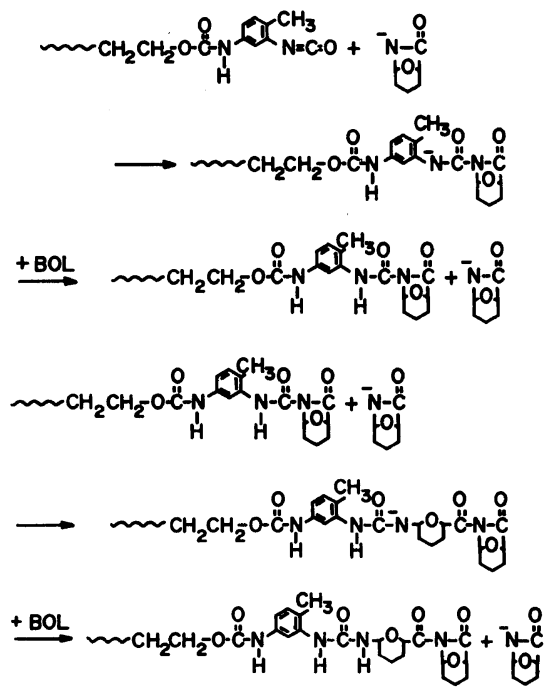

ization of BOL (1) proceeded easily in $\mathrm{Me}_{2} \mathrm{SO}$ at $25^{\circ} \mathrm{C}$ to give the acetone-insoluble polymer in high yield as summarized in Table II.

In Figure 2, the gel permeation chromatographs show that the resulting polymer is not contaminated by the unreacted feed polyoxyethylene. In the ${ }^{1} \mathrm{H}$ NMR spectrum, however, all the peaks due not only to the repeating unit in the polyBOL chain but also to the polyoxyethylene chain were detected (see Figure 3). Additional characteristic peaks $d_{1}$ and $d_{2}$ in the spectrum should be assignable to the oxyethylene unit adjacent to the biscarbamic acid ester unit, so that a block copolymer composed of both polyamide and polyoxyethylene segments should be found.

A small amount of the unreacted polyoxyethylene was in the acetone phase after recovery of the resulting polymer. A trace amount of the contaminated moisture probably deactivated some of the terminal isocyanate groups in the activator.

The efficiency of block copolymerization, defined as the weight ratio of the polyoxyethylene consumed as an activator, to the polyoxyethylene fed, was calculated from the copolymer composition and polymer yield, as presented in Table II. From Table II the 
Table II. Anionic polymerization of BOL with use of polyoxyethylene having terminal isocyanate groups as activators ${ }^{\mathrm{a}}$

\begin{tabular}{|c|c|c|c|c|c|c|c|c|c|}
\hline \multirow{2}{*}{$\begin{array}{l}\text { Run } \\
\text { No. }\end{array}$} & \multirow{2}{*}{$\frac{\mathrm{BOL}}{\mathrm{g}}$} & \multicolumn{2}{|c|}{$\cdot \mathrm{POE}-\mathrm{NCO}^{\mathbf{b}}$} & \multirow{2}{*}{$\frac{\mathrm{Me}_{2} \mathrm{SO}}{\mathrm{ml}}$} & \multirow{2}{*}{$\frac{\text { Time }}{\mathrm{h}}$} & \multirow{2}{*}{$\frac{\text { Yield }^{\mathrm{c}}}{\mathrm{g}}$} & \multicolumn{2}{|c|}{ BOL unit in copolymer } & \multirow{2}{*}{$x^{\mathrm{d}}$} \\
\hline & & $M_{n}$ & g & & & & Mole fraction & Weight fraction & \\
\hline 1 & 5.65 & 1550 & 0.88 & 25 & $24^{\mathrm{e}}$ & 5.12 & 0.68 & 0.85 & 0.97 \\
\hline 2 & 9.52 & 3110 & 1.92 & 33 & $2^{\mathrm{e}}$ & 8.15 & 0.69 & 0.87 & 0.56 \\
\hline 3 & 4.50 & 3250 & 0.98 & 16 & $1^{\mathrm{f}}$ & 3.88 & 0.53 & 0.77 & 0.93 \\
\hline
\end{tabular}

${ }^{\text {a }}$ Polymerization conditions: potassium pyrrolidonate; $1 \mathrm{~mol} \%$ to $\mathrm{BOL}$; temperature, $25^{\circ} \mathrm{C}$.

b Isocyanate-terminated polyoxyethylene.

c Acetone insoluble polymer.

d Efficiency of block copolymerization estimated from the weight ratio of polyoxyethylene in the copolymer to that in the feed.

e Under a dry nitrogen atmosphere.

f In high vacuum.

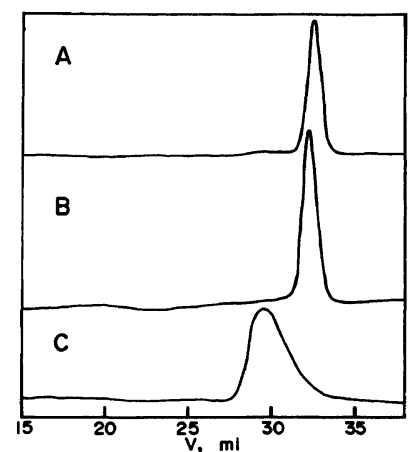

Figure 2. GPC curves of polymers (column, Shodex GPCA $80 \mathrm{M}, 8 \phi \times 1000 \mathrm{~mm}$; solvent, chloroform): A, polyoxyethylene glycol $\left(M_{n}, 2850\right)$; B, reaction product of polyoxyethylene having terminal isocyanate groups with ethanol $\left(M_{n}, 3340\right)$; C, block copolymer composed of polyBOL and polyoxyethylene segments.

polymerization procedure in a vacuum line is considered preferable to that under a dry nitrogen atmosphere for preparing the block copolymer containing a high molecular weight polyoxyethylene segment. With relatively low molecular weight polyoxyethylene having terminal isocyanate groups, the efficienoy was high, even when the procedure was carried out under a dry nitrogen atmosphere.

All the polyamide segments formed in the present reaction system may be considered as coupled favorably with the polyoxyethylene segment, since a trace amount of concomitant

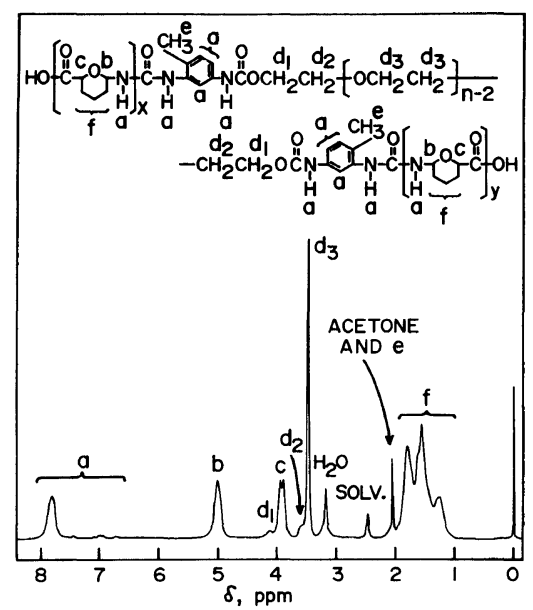

Figure 3. ${ }^{1} \mathrm{H}$ NMR spectrum of copolymer obtained by anionic polymerization of BOL activated by telechelic polyoxyethylene with isocyanate groups $\left(M_{n}, 1550\right)$ in $\mathrm{Me}_{2} \mathrm{SO}$ at $25^{\circ} \mathrm{C}\left(8 \% \mathrm{Me}_{2} \mathrm{SO}-d_{6}\right.$ solution, TMS, $60^{\circ} \mathrm{C}$, $200 \mathrm{MHz}$ ).

moisture would not destroy the resulting acyltype growing species although it could bring about a decrease in the concentration of the BOL monomer anion. ${ }^{8}$ The number average molecular weights of the block copolymers obtained on the run No. 1 and 3 in Table II may thus be about 9000 and 12000, respectively, from the polymer yield and copolymer composition. However, this could not be determined directly by the vapor pressure or 
membrane osmometries owing to their high hygroscopicity.

A typical block copolymer with a weight fraction of the polyamide segments of 0.77 was soluble not only in $m$-cresol, trifluoroethanol, hexafluoro-2-propanol, and dimethyl sulfoxide, but also in chloroform, $N, N$ dimethylformamide, and pyridine, which could not dissolve the high molecular weight homopolymer of $\mathrm{BOL}$, at room temperature. The copolymer swelled in methanol and ethanol and insoluble in acetone, ethyl acetate, and water, which could solubilize POE-OH $\left(M_{n}, 2850\right)$.

Figure 4 shows moisture isotherms of the block copolymer composed of polyBOL and polyoxyethylene segments and their homopolymers, as determined at $20^{\circ} \mathrm{C}$ on coarsely ground samples. As described before, ${ }^{1,2}$ the amount of moisture adsorbed on the homopolymer of BOL is much more than that of either nylon 4 or nylon 6 at any relative humidity and is, roughly speaking, comparable to that of wool and silk. It should be noted that the hygroscopicity of the block copolymer was lower than that of the homopolymer of BOL at a lower but not higher relative humidity. This fact corresponds to the low ability of water sorption of polyoxyethylene glycol at a lower relative humidity al- though the glycol is soluble in water. The polyoxyethylene segment in the solid block copolymer may have an ordered structure similar to that of the polyoxyethylene glycol; i.e., it may form a kind of microdomain.

\section{Hydrophilic Block Copolymer Membrane}

The block copolymer membrane was easily obtained by casting from the copolymer solution in a chloroform-methanol $(10: 1) \mathrm{mix}$ ture and drying at room temperature. As shown in Table III, the degree of hydration for the resulting membrane was higher than that for the polyBOL membrane prepared by the same casting method. This may indicate not

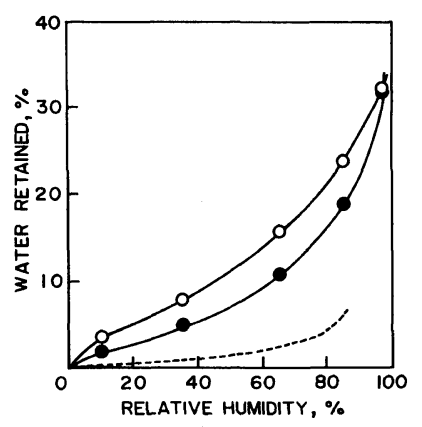

Figure 4. Moisture sorption isotherms of various polymers at $20^{\circ} \mathrm{C}$ : $\bigcirc$, polyBOL; $\bigcirc$, block copolymer composed of polyBOL and polyoxyethylene segments (weight fraction of polyBOL segments, 0.77); ---, polyoxyethylene glycol $\left(M_{n}, 2850\right)$.

Table III. Water permeation of various membranes under a pressure difference of $2 \mathrm{~kg} / \mathrm{cm}^{2}$ at $25^{\circ} \mathrm{C}$

\begin{tabular}{|c|c|c|c|c|c|}
\hline \multirow{2}{*}{ Membrane } & \multirow{2}{*}{$\begin{array}{l}\text { Degree of } \\
\text { hydration }^{a}\end{array}$} & \multirow{2}{*}{$\begin{array}{c}\text { Wet } \\
\text { thickness } \\
\mu \mathrm{m}\end{array}$} & \multirow{2}{*}{$\frac{\text { Water flux }}{1 \mathrm{~m}^{-2} \cdot \mathrm{h}^{-1}}$} & \multirow{2}{*}{ 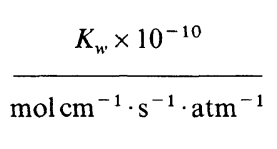 } & \multirow{2}{*}{ Ref } \\
\hline & & & & & \\
\hline Crosslinked cellulose & 0.62 & 32 & 1.5 & 37 & 10 \\
\hline Block copolymer ${ }^{\mathrm{b}}$ & 0.47 & 72 & 0.15 & 8.4 & This work \\
\hline PolyBOL & 0.28 & 64 & 0.066 & 3.3 & 12 \\
\hline $\mathrm{CDA}^{\mathrm{c}}$ & 0.17 & 3.7 & 0.049 & 0.16 & 10 \\
\hline $\mathrm{PMLG}^{\mathrm{d}}$ & 0.11 & 7.4 & 0.26 & 1.5 & 13 \\
\hline
\end{tabular}

a Volume fraction of water in membrane.

b Block copolymer of polyBOL and polyoxyethylene segments (weight fraction of polyBOL segments, 0.77 ).

c Cellulose diacetate.

d Poly $(\gamma$-methyl L-glutamate). 
only the high hydrophilicity of the polyBOL segments but also that of the polyoxyethylene segment.

The water flux $\left(1 \mathrm{~m}^{-2} \cdot \mathrm{h}^{-1}\right)$ for the membrane was measured under a pressure difference of $1-4 \mathrm{~kg} \mathrm{~cm}^{-2}$ at $15-45^{\circ} \mathrm{C}$, using a commercial ultrafiltration cell. The value of the hydraulic permeability for the membrane, $K_{w}$, is given by eq $4 .^{14,15}$

$$
J_{w}=K_{w} \Delta p / \Delta x
$$

where $J_{w}$ and $\Delta p / \Delta x$ are the water flux and pressure gradient, respectively.

As expected from its high water content, ${ }^{16}$ the value of $K_{w}$ for the copolymer membrane at $25^{\circ} \mathrm{C}$ was significantly higher than those for the polyBOL, cellulose diacetate, and $\operatorname{poly}(\gamma$ methyl L-glutamate) membranes.

Differential scanning calorimetry can be used to observe the adsorption behavior of water molecules in various polymer membranes and gels. ${ }^{6,17-20}$ The DSC thermograms of the wet copolymer membrane indicate that the membrane can adsorb more than $0.4 \mathrm{~g}$ of non-freezing water per gram of dry polymer (curve $\mathrm{A}$ in Figure 5). With an increase of water content in the membrane, a broad endothermic peak emerged at $-5-3^{\circ} \mathrm{C}$ and subsequently, another one at $2^{\circ} \mathrm{C}$. Both should be due to the fusion of frozen water. Since the frozen water in the wet polyBOL membrane has only one sharp melting point around $0^{\circ} \mathrm{C},{ }^{6}$ the broad peak observed in the present system suggests the existence of many clusters or loosely-bound water probably in the region of the polyoxyethylene domain or boundary regions among the polyBOL and polyoxyethylene domains. The amount of nonfreezing water in the membrane was estimated to be $0.55 \mathrm{~g}$ per gram of the dry polymer from the relationship between the amount of water adsorbed in the membrane and heat of fusion of frozen water, as shown in Figure 6. The value is higher than that obtained for the polyBOL membrane, $0.42 \mathrm{~g}$ per gram of dry polymer, which correspond to $3 \mathrm{~mol}$ of water

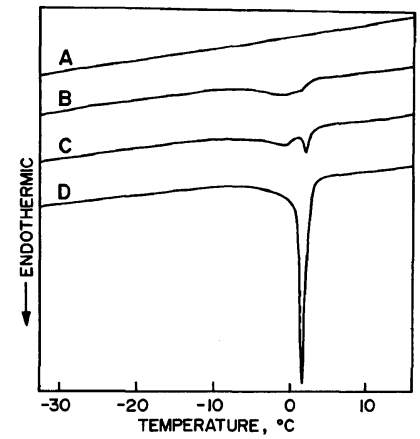

Figure 5. DSC thermograms of a wet block copolymer membrane composed of polyBOL and polyoxyethylene segments (weight fraction of polyBOL segments, 0.77). Heated at $5^{\circ} \mathrm{C} \mathrm{min}^{-1}$ after keeping at $-60^{\circ} \mathrm{C}$ for more than $20 \mathrm{~min}$. $\mathrm{gH}_{2} \mathrm{O} / \mathrm{g}$ dry polymer: $\mathrm{A}, 0.40 ; \mathrm{B}, 0.61$; , $0.82 ; \mathrm{D}, 1.07$.

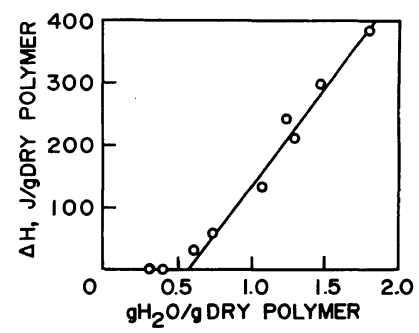

Figure 6. Relationship between heat of fusion of water around $0^{\circ} \mathrm{C}$ and its content in a block copolymer membrane composed of polyBOL and polyoxyethylene segments (weight fraction of polyBOL segments, 0.77 ).

per BOL monomer unit. If $3 \mathrm{~mol}$ of nonfreezing water correspond to one $\mathrm{BOL}$ unit even in the polyBOL segment in the block copolymer membrane, another $2.4 \mathrm{~mol}$ of nonfreezing water may be allotted to one oxyethylene unit in the polyoxyethylene segment.

The heat of fusion of frozen water in the membrane was computed from the gradient of the straight line in Figure 6, and is listed in Table IV along with those for various polyamide membranes. ${ }^{6}$ It is noteworthy that the estimated value of heat of fusion of frozen water in the block copolymer membrane was not only lower than that of normal ice $\left(333 \mathrm{~J} \mathrm{~g}^{-1}\right)$ but also than those of frozen water in the polyBOL and nylon 6 membranes. The low value of the heat of fusion of frozen water 
Table IV. Content of non-freezing water and heats of fusion of frozen water in various membranes

Polymer $\begin{aligned} & \text { Content of non- } \\ & \text { freezing water }\end{aligned}$ of frozen water
Block copolymer
PolyBOL
Nylon 6

\section{REFERENCES}

1. H. Sumitomo and K. Hashimoto, Macromolecules,
10, 1327 (1977).

2. K. Hashimoto and H. Sumitomo, Macromolecules, 13, 786 (1980).

3. K. Hashimoto and H. Sumitomo, J. Polym. Sci., Polym. Chem. Ed., 21, 397 (1983).

4. H. Sumitomo, K. Hashimoto, and T. Ohyama, Polym. Bull., 1, 133 (1978).

5. H. Sumitomo, K. Hashimoto, and T. Ohyama, Polym. Bull., 1, 635 (1979).

6. H. Sumitomo and K. Hashimoto, "Contemporary Topics in Polymer Science," Vol. 4, W. J. Bailey and T. Tsuruta Ed., Plenum, New York, N. Y., 1984, p 779.

7. K. Hashimoto and H. Sumitomo, Polym. J., 15, 547 (1983).

8. K. Hashimoto, H. Sumitomo, and M. Kawasumi, Polym. Bull., 11, 121 (1984).

9. H. Sekiguchi, Bull. Soc. Chim. Fr., 1827 (1960).

10. M. Kawaguchi, T. Taniguchi, K. Tochigi, and A. Takizawa, J. Appl. Polym. Sci., 19, 2515 (1975).

11. A. Noshay and J. E. McGrath, "Block CopolymersOverview and Critical Survey," Academic Press, New York, N. Y., 1977, p. 365.

12. K. Hashimoto, H. Sumitomo, and K. Terajima, unpublished data.

13. A. Takizawa, T. Taniguchi, I. Yamamuro, Y. Tsujita, T. Nakagawa, and N. Minoura, $J$. Macromol. Sci.-Phys., B13, 203 (1977).

14. K. S. Spiegler, Trans. Faraday Soc., 54, 1508 (1958).

15. O. Kedem and A. Katchalsky, J. Gen. Physiol., 45, 143 (1961).

16. H. Yasuda, C. E. Lamaze, and A. Peterlin, J. Polym. Sci., A-2, 9, 1117 (1971).

17. M. A. Frommer and D. Lancet, J. Appl. Polym. Sci., 16, 1295 (1972).

18. Y. Taniguchi and S. Horigome, J. Appl. Polym. Sci., 19, 2743 (1975).

19. M. Takami, F. Hori, R. Kitamaru, and Y. Ikada, Polym. Prepr., Jpn., 25, 426 (1976).

20. K. Nakamura, T. Hatakeyama, and H. Hatakeyama, Text. Res. J., 51, 607 (1981). 